\title{
ÇARPMA YÜKÜ ALTINDAKİ RİJİT PLASTİK KİRİ̧̧ERİN ANALİTİK OLARAK İNCELENMESİ
}

\author{
Tekin GÜLTOP ${ }^{1}$, Mahmut Cem YILMAZ ${ }^{2}$, Bahadır ALYAVUZ ${ }^{2}$ \\ ${ }^{1}$ Çankaya Üniversitesi, Mühendislik Fakültesi, İnşaat Mühendisliği Bölümü, Etimesgut 06790, Ankara \\ ${ }^{2}$ Gazi Üniversitesi, Mühendislik Fakültesi, İnşaat Mühendisliği Bölümü, Maltepe 06570, Ankara \\ tgultop@cankaya.edu.tr, mcyilmaz@gazi.edu.tr, balyavuz@gazi.edu.tr
}

(Geliş/Received: 14.03.2014; Kabul/Accepted: 11.07.2014)

ÖZET

Kirişler, kullanım ömürleri boyunca dinamik bir yükleme türü olan çarpma yüklerine maruz kalabilirler. Bu çalışmada kirişlerin düşük hızlı çarpma yükü etkisi altındaki davranışları analitik olarak incelenmiştir. Basit ve ankastre mesnetli kirişler, rijit plastik davranış kabulü yapılarak dinamik yükler altında incelenmiştir. Göçme mekanizmasının ani olarak plastik mafsal oluşumuyla gerçekleştiği kabul edilmiş, enerji ve momentumun korunma ilkeleri dikkate alınarak dinamik yük altında kirişlerin limit analizi yapılmıştır. Darbe yükü altındaki rijit plastik kiriş davranışı, benzer yükleme koşulları altındaki elastik kiriş davranışıyla karşılaştırılmıştır.

Anahtar Kelimeler: Rijit plastik kirişler, enerji ve momentumun korunumu, çarpma yükü, plastik mafsal

\section{AN ANALYTICAL INVESTIGATION OF RIGID PLASTIC BEAMS UNDER IMPACT LOADING}

\begin{abstract}
Beams might be subjected to impact loading which is a particular type of dynamic loading during their service lives. In this study the behaviour of beams under low speed impact loading has been investigated analytically. Simply supported and fixed ended beams have been analyzed with the assumption of rigid plastic behaviour. The collapse mechanism has been assumed to emerge by the instant formation of plastic hinges, hence, a limit analysis has been performed under dynamic loading considering the conservation principles of energy and momentum. The behaviour of rigid plastic beams under impact loading has been compared to the behaviour of elastic beams under similar loading conditions.
\end{abstract}

Keywords: Rigid plastic beams, conservation of energy and momentum, impact loading, plastic hinge

\section{GIRIŞ̧ (INTRODUCTION)}

Yapı elemanları kullanım ömürleri boyunca bir dinamik yükleme çeşidi olan çarpma yükü etkisine maruz kalabilirler. Bu yükleme tipi köprü ayaklarına bir aracın çarpması, sanayi yapılarında döşeme veya kiriş üzerine bir ağırlık düşmesi, askeri yapılarda patlama sonucunda cisimlerin yapı elemanlarına çarpması gibi birçok örnek durumda ortaya çıkabilir. Çarpma olayı, düşük hızlı çarpma ve yüksek hızlı çarpma olarak ikiye ayrılabilir. Beton bir bloğa mermi saplanması gibi durumlar yüksek hızlı çarpmanın; betonarme bir döşeme üzerine bir ağırlığın serbest olarak düşmesi gibi durumlar da düşük hızlı çarpmanın örnekleri olarak nitelenebilir. Geçmişte çarpma yükü etkisi altındaki yapı elemanlarının davranışları ile ilgili teorik ve deneysel olarak bazı çalışmalar yapılmıştır. J.L. Yang ve arkadaşları rijit plastik malzeme davranışı kabulü yaparak iki konsol kirişin uçlarına G kütlesinin çarpması durumunu [1], serbest düşürülen bir kirişin aşağıdaki konsol bir kirişe çarpması durumunu [2], bir kirişin iki ucu ankastre mesnetli bir kirişe çarpması durumunu [3] ve herhangi bir noktasından ani bir P yüklemesine maruz kalan serbest kirişin davranışını [4] teorik olarak incelemişlerdir. Bunların dışında iki ucu ankastre mesnetli kirişin açıklığının herhangi bir noktasından düşük hızlı çarpma yüküne maruz kalması durumundaki davranışı ile ilgili teorik olarak başka çalışmalar da yapılmıştır [5-6]. Teorik çalışmaların yanısıra deneysel veya nümerik olarak yalın beton, betonarme, çelik veya kompozit kirişlerin çarpma 
etkisi altındaki davranışları ile ilgili çeşitli çalışmalar yapılmıştır. E. Kantar ve arkadaşları, [7] beton basınç dayanımındaki değişimin beton kirişlerin çarpma yükü altındaki davranışları üzerinde çalışmışlardır. Çalışmalarında serbest ağırlık düşürme deney düzeneğini kullanmışlardır. N. Kishi ve A. Q. Bhatti, [8] betonarme kirişlerin çarpma etkisi altındaki davranışı ile ilgili olarak bir sonlu eleman yöntemi geliştirmişler ve bunu doğrulamak için bir deney yapmışlardır. S. Saatci ve F. J. Vecchi, kesme dayanımının çarpma yükü etkisi altındaki betonarme kirişlerin davranışına etkisini deneysel [9] ve nümerik [10] olarak araştırmışlardır. Nümerik çalışmada kirişlerin dinamik davranışını öngörebilmek için bir sonlu elemanlar analiz yöntemi önermişler ve bir yazılım geliştirmişlerdir. R. Harsoor ve L.S. Ramachandra, [11] yumuşak çelikten üretilmiş çentikli veya çentiksiz kirişler üzerinde deneyler yapmış ve deneyleri bir sonlu elemanlar programı olan ANSYS ile modellemişlerdir. M.R. Bambacha ve arkadaşları, [12] beton dolgulu kompozit kirişlerin düşük hızlı yükleme altındaki davranışlarını hem teorik hem de deneysel olarak araştırmışlardır.

$\mathrm{Bu}$ çalışmada T. Gültop, B. Alyavuz ve M.C. Yılmaz'ın rijit plastik kirişlerle ilgili daha önce yapmış oldukları çalışma [13] esas alınarak kirişlerin düşük hızlı çarpma yükü etkisi altındaki davranışları analitik olarak incelenmiştir. Çalışmada iki ucu basit veya iki ucu ankastre mesnetle mesnetlenmiş " $\mathrm{M}_{1}$ " kütlesindeki bir kirişin açıklığının orta noktasına " $\mathrm{h}$ " yüksekliğinden serbest bırakılan " $\mathrm{M}$ " kütlesindeki ağırlığın çarpması durumunda kirişin göstereceği davranış ele alınmıştır. Çalışmanın ilk kısmında basit mesnetli rijit plastik kiriş ve basit mesnetli elastik kiriş için enerji sönümleme oranı değerleri hesaplanarak karşılaştırma yapılmıştır. Daha sonra basit mesnetli rijit plastik kiriş ve ankastre mesnetli rijit plastik kiriş için dönme açıları hesaplanarak karşılaştırılmıştır. Eşitlikler türetilirken momentumun korunumundan ve enerji denklemlerinden faydalanılmıştır.

\section{ANALİTIKK ÇALIŞMA (ANALITICAL WORK)}

Çalışmada bazı kabuller yapılmıştır. $\mathrm{Bu}$ kabuller aşağıdaki gibidir:

Çarpışmanın "tam plastik çarpışma türünde" gerçekleştiği kabul edilmiştir. Bu kabule göre, serbest bırakılan bir cismin düşmesi ile gerçekleşen çarpma sonucunda, düşen cisim, kiriş orta noktasına yapışmakta ve kiriş orta noktası ile birlikte aynı hızla hareket etmektedir. Bu çarpma türü için geçerli olan tam plastik çarpma katsayısı (the coefficient of restitution), 1'e eşittir. Tam plastik çarpışmada momentum korunmakta, fakat enerji korunmamaktadır. Çarpışmanın ideal koşullarda gerçekleştiği kabul edilmiştir. Kiriş ve kirişe çarpan kütle arasında düzgün bir deformasyon ve gerilme aktarımı olmaktadır.
Göçmenin plastik mafsal oluşumu nedeniyle ani olarak gerçekleştiği kabul edilmiştir. Bu nedenle, çarpma sonrasında kiriş boyunca oluşabilecek dalga yayılması ile titreşim etkileri, ikinci dereceden etkiler olarak değerlendirilmiş ve mevcut çalışma kapsamında ihmal edilmiştir.

2.1. Basit Mesnetli Rijit Plastik Kiriş için Enerji Sönümleme Oranı $K_{p}$ (The Energy Dissipation Ratio $K_{p}$ for a Simply Supported Rigid Plastic Beam)

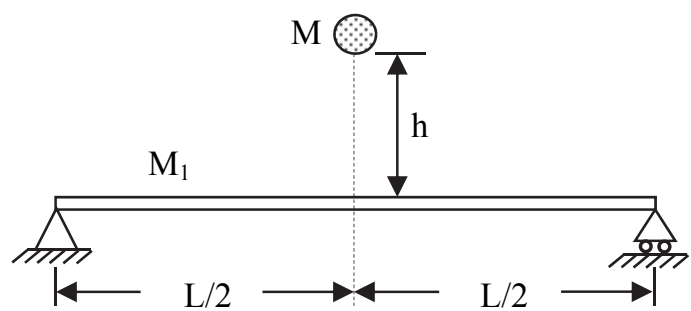

Şekil 1. Basit mesnetli bir kiriş üzerine $M$ kütlesinin düşürülmesi (The free fall of a mass $M$ on to the simply supported beam)

Şekil 1'de basit mesnetli $\mathrm{M}_{1}$ kütlesindeki bir kirişin açıklık orta noktasına $h$ yüksekliğinden $M$ kütlesindeki bir ağırlık düşürülmektedir. Bu bölümde Şekil 1'de gösterilen basit mesnetli kirişin rijit plastik cisim davranışı gösteren bir kiriş olması durumu ele alınmıştır. Buna göre, çarpışma ile kiriş orta noktasında plastik mafsal oluşmakta ve mafsalın iki tarafındaki kiriş parçaları kendi eksenleri boyunca doğrusal kalarak mafsal etrafında dönmekte ve kiriş göçmektedir (Şekil 2). Çalışmada basit mesnetli rijit plastik kirişin çarpışmada enerji sönümleme oranı, $\mathrm{K}_{\mathrm{p}}$ olarak adlandırılmıştır ve,

$$
\mathrm{K}_{\mathrm{p}}=\frac{\left(\mathrm{T}_{1}\right)_{\mathrm{p}}}{\left(\mathrm{T}_{0}\right)_{\mathrm{p}}}
$$

denklemi ile ifade edilmiştir. $\left(\mathrm{T}_{0}\right)_{\mathrm{p}}$ ve $\left(\mathrm{T}_{1}\right)_{\mathrm{p}}$, sırasıyla çarpışmanın hemen öncesinde ve sonrasında rijit plastik kiriş ve $M$ kütlesinden oluşan sistemin sahip olduğu toplam kinetik enerjiyi göstermektedir.

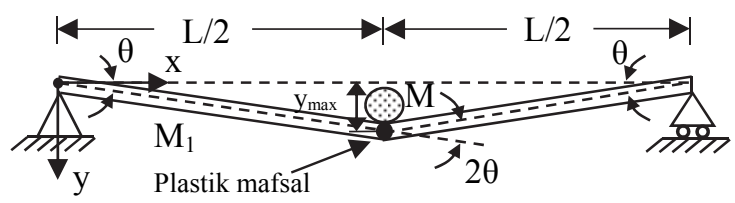

Şekil 2. Basit mesnetli rijit plastik kirişin çarpışmadan hemen sonraki hareketi (The motion of a simply supported rigid plastic beam just after impact)

$\left(T_{0}\right)_{p}$ ’nin bulunması: Çarpışmanın hemen öncesinde (Şekil 3) kiriş hareketsiz olduğu için kirişin kinetik enerjisi sıfırdır. Bu durumda çarpışmadan hemen önceki toplam kinetik enerji $\mathrm{M}$ kütlesinin o andaki kinetik enerjisine eşittir. Çarpışmadan hemen önce $M$ kütlesinin hızına $v_{0}$ denildiğinde çarpışma öncesindeki toplam kinetik enerji denklem (2) ile ifade edilir. 
$\left(\mathrm{T}_{0}\right)_{\mathrm{p}}=\frac{1}{2} \mathrm{Mv}_{0}^{2}$

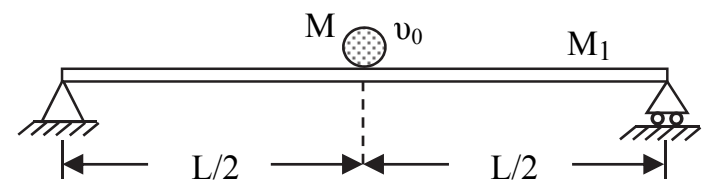

Şekil 3. Kiriş ve $M$ kütlesinin çarpışmadan hemen önceki konumu (Positions of beam and mass $\mathrm{M}$ just before impact)

$\left(T_{1}\right)_{p}$ 'nin bulunmast: L uzunluğundaki rijit plastik kirişin Şekil 4'de gösterildiği gibi L/2 uzunluğundaki parçası ele alınmıştır. Çarpışma ile birlikte kiriş orta noktasında plastik mafsal oluşmakta ve kiriş orta noktası ile kirişe yapışan M kütlesi aynı doğrultuda ve aynı hızla hareket etmektedirler. Çarpışmanın hemen sonrasındaki toplam kinetik enerji $\left(\mathrm{T}_{1}\right)_{\mathrm{p}}$,

$\left(\mathrm{T}_{1}\right)_{\mathrm{p}}=\frac{1}{2} \mathrm{M} \mathrm{v}_{1}{ }^{2}+2 \int_{0}^{\mathrm{L} / 2} \frac{1}{2} \rho\left(v_{\mathrm{x}}\right)^{2} \mathrm{dx}$

eşitliği ile bulunur.

Eşitlikte geçen $\rho$ kirişin birim boyunun ağırlığını, $v_{x}$ kiriş üzerindeki mesnetten $\mathrm{x}$ kadar mesafedeki bir noktanın düssey hızını göstermektedir. Eşitliğin sağındaki ilk ifade $\mathrm{M}$ kütlesinin, ikinci ifade ise kirişin, çarpışma sonrasındaki kinetik enerjilerini göstermektedir.

Rijit plastik davranışın geometrisi gereğince, hız mesnete olan $\mathrm{x}$ mesafesi ile doğru orantılı olarak değişmektedir. Kiriş orta noktası ve $M$ kütlesinin ortak hızına $v_{1}$ denildiğinde $v_{x}$ denklem (4)'deki gibi bulunur. Denklem (3)'de $\rho$ yerine $M_{1} / L$ ve $v_{x}$ yerine de denklem (4)'deki ifade konulup integral alındığında denklem (5) elde edilmiş olur.

$v_{x}=\frac{2 v_{1} x}{L}$

$\left(\mathrm{T}_{1}\right)_{\mathrm{p}}=\left(\frac{\mathrm{M}}{2}+\frac{\mathrm{M}_{1}}{6}\right) \mathrm{v}_{1}^{2}$

Denklem (2) ve denklem (5), denklem (1)'de yerine konulduğunda " $\mathrm{K}_{\mathrm{p}}$ " aşă̆ıdaki gibi bulunur.

$\mathrm{K}_{\mathrm{p}}=\frac{\frac{\mathrm{M}}{2}+\frac{\mathrm{M}_{1}}{6}}{\frac{\mathrm{M}}{2}}\left(\frac{v_{1}}{v_{0}}\right)^{2}$

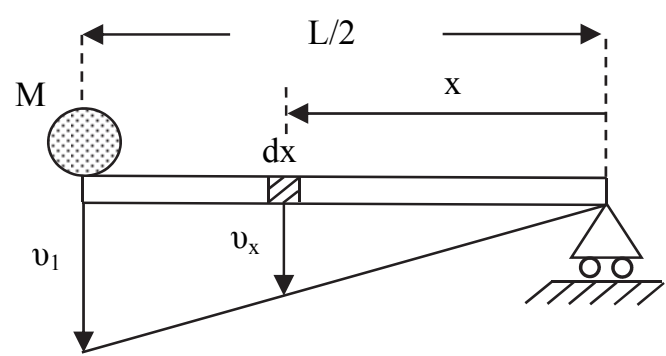

Şekil 4. Çarpışma sonrasında rijit plastik kiriş üzerindeki bir noktanın hızı (The velocity of an arbitrary point on the rigid plastic beam after impact)

Momentumun korunumu: Tam plastik çarpışmada momentum korunmaktadır. Burada M kütlesi ve rijit plastik kirişten oluşan sistemin çarpışma öncesindeki ve sonrasındaki momentumlarına sirasıyla $\left(L_{0}\right)_{p}$ ve $\left(\mathrm{L}_{1}\right)_{\mathrm{p}}$ denilmiştir. Çarpışmadan hemen önce kiriş hareketsiz olduğu için, o andaki momentum sadece M kütlesinin momentumundan ibarettir (Denklem (7)).

$$
\left(\mathrm{L}_{0}\right)_{\mathrm{p}}=\mathrm{Mv}_{0}
$$

Kiriş parçalarından her birinin kütle merkezindeki hız, veya kiriş boyunca ortalama hız $v_{1} / 2$ 'dir. Buna göre çarpışma sonrasındaki momentum,

$$
\left(\mathrm{L}_{1}\right)_{\mathrm{p}}=\mathrm{Mv}_{1}+\mathrm{M}_{1} \frac{v_{1}}{2}
$$

denklemi ile ifade edilir. Çarpışmada momentum korunduğundan denklem (7) ve denklem (8) birbirine eşitlendiğinde ve $v_{1} / v_{0}$ ifadesi yeni eşitliğin sol tarafında yalnız bırakıldığında,

$$
\frac{v_{1}}{v_{0}}=\left(\frac{1}{1+\frac{M_{1}}{2 M}}\right)
$$

denklemi elde edilir. Denklem (9), denklem (6)'da ilgili yere konulduğunda $K_{p}$ ifadesi, çarpan cismin kütlesi $\mathrm{M}$ 'e ve rijit plastik kirişin kütlesi $\mathrm{M}_{1}$ 'e bağl1 olarak denklem (10)'daki gibi bulunur.

$\mathrm{K}_{\mathrm{p}}=\frac{1+\frac{\mathrm{M}_{1}}{3 \mathrm{M}}}{\left(1+\frac{\mathrm{M}_{1}}{2 \mathrm{M}}\right)^{2}}$

\subsection{Basit Mesnetli Elastik Kiriş için Enerji Sönümleme Oranı $K_{e}$ (The Energy Dissipation Ratio $K_{e}$ for a Simply Supported Elastic Beam)}

[14] numaralı kaynakta verilmiş olan basit mesnetli elastik kiriş için enerji sönümleme oranı $\mathrm{K}_{\mathrm{e}}$ burada denklem (11) ile gösterilmiştir. 
Bu bölümde Şekil 1'de gösterilen kirişin elastik cisim davranışı yapan bir kiriş olması durumu ele alınarak denklem (11) türetilmeye çalışılmıştır.

$$
\mathrm{K}_{\mathrm{e}}=\frac{1+\frac{17 \mathrm{M}_{1}}{35 \mathrm{M}}}{\left(1+\frac{5 \mathrm{M}_{1}}{8 \mathrm{M}}\right)^{2}}
$$

Basit mesnetli elastik kiriş çarpma etkisi altında Şekil 5 'deki gibi deformasyon yapar.

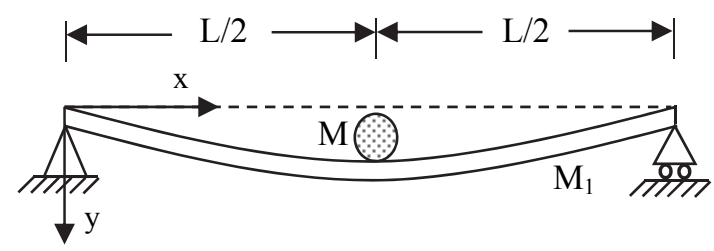

Şekil 5. Çarpışma sonrası basit mesnetli elastik kiriş deformasyonu (The deformation of a simply supported elastic beam after impact)

$\mathrm{K}_{\mathrm{e}}$ 'nin genel ifadesi $\mathrm{K}_{\mathrm{p}}$ 'ye benzer şekilde denklem (12)'de verilmiştir.

$\mathrm{K}_{\mathrm{e}}=\frac{\left(\mathrm{T}_{1}\right)_{\mathrm{e}}}{\left(\mathrm{T}_{0}\right)_{\mathrm{e}}}$

Denklem (12)'de geçen $\left(\mathrm{T}_{0}\right)_{\mathrm{e}},\left(\mathrm{T}_{1}\right)_{\mathrm{e}}$ ifadeleri sırasıyla $M_{1}$ kütlesindeki elastik kiriş ve $M$ kütlesindeki ağırlığın çarpışmadan hemen önceki ve hemen sonraki toplam kinetik enerjilerini göstermektedir. Bir cisim $\Delta \mathrm{t}$ kadar sürede y mesafesi kadar yol alıyorsa bu cismin ortalama hizı $v_{\text {ort, }}$,

$v_{\text {ort }}=\frac{\mathrm{y}}{\Delta \mathrm{t}}$

denklemi ile bulunur. Şekil 5'deki deforme olmuş bir kirişin elastik eğri denklemi kullanılarak, kiriş üzerindeki herhangi bir noktanın çarpışma sonrasındaki hızı denklem (13) yardımı ile bulunabilir. Basit mesnetli elastik bir kiriş, açıklığının orta noktasına statik P yükü etki etmesi halinde Şekil 5'deki gibi deforme olur. Buna göre, kiriş orta noktasına $\mathrm{P}$ yükü etki etmesi halinde $\mathrm{x}<\mathrm{L} / 2$ için türetilmiş olan elastik eğri denklemi (Denklem (14)) Şekil 5'deki kirişin elastik eğrisi için de kullanılabilir.

$\mathrm{y}=\frac{1}{\mathrm{EI}}\left(\frac{\mathrm{Px}^{3}}{12}-\frac{\mathrm{PL}^{2} \mathrm{x}}{16}\right)$

Denklem (14)'de "I" kiriş kesitinin ağırlık merkezinden geçen eksene göre atalet momentini, "E" ise kiriş malzemesinin elastisite modülünü göstermektedir.
$\left(T_{0}\right)_{e}$ nin bulunması: Basit mesnetli rijit plastik kirişte olduğu gibi (Şekil 3) çarpışmadan hemen önce M ütlesinin hızına $v_{0}$ denildiğinde ve o anda kiriş hareketsiz olduğundan $\left(\mathrm{T}_{0}\right)_{\mathrm{e}}, \mathrm{M}$ kütlesinin kinetik enerjisine eşit olacaktır (Denklem (15)).

$$
\left(\mathrm{T}_{0}\right)_{\mathrm{e}}=\frac{1}{2} \mathrm{Mv}_{0}^{2}
$$

$\left(T_{1}\right)_{e}$ 'in bulunmast: Rijit plastik kirişte olduğu gibi, çarpışma sonrasında $M$ kütlesi ile elastik kirişin ortak hızına da $v_{1}$ denilmiştir. L uzunluğundaki elastik kirişin Şekil 6'da gösterildiği gibi L/2 uzunluğundaki parçası ele alınmıştır. Şekil 6'da görüldüğü gibi, kiriş üzerindeki bir noktanın hızı, o noktanın elastik eğride görülen düşey deplasmanla orantılı olacaktır.

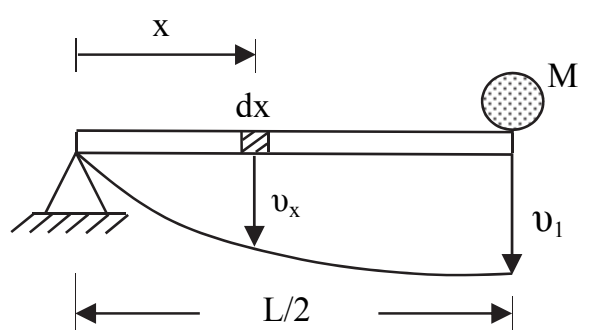

Şekil 6. Çarpışma sonrasında elastik kiriş üzerindeki bir noktanın hizı ( The velocity of an arbitrary point on the elastic beam after impact)

Şekil 6'da kiriş üzerinde mesnetten $\mathrm{x}$ kadar uzaklıktaki bir noktanın hızına $v_{\mathrm{x}}$ denildiğinde $\left(\mathrm{T}_{1}\right)_{\mathrm{e}}$,

$\left(T_{1}\right)_{e}=\frac{1}{2} M v_{1}{ }^{2}+2 \int_{0}^{L / 2} \frac{1}{2} \rho\left(v_{x}\right)^{2} d x$

denklemindeki gibi ifade edilir. Denklemin sağ tarafındaki ilk kısım M kütlesinin kinetik enerjisini göstermektedir. Denklemin sağındaki ikinci kısım ise elastik kirişin çarpışma sonrasındaki kinetik enerjisini göstermektedir. Denklem (13)'de $v_{\text {ort }}$ yerine $v_{\mathrm{x}}$ ve y yerine de denklem (14)'deki ifade konulduğunda $v_{x}$, denklem (17)'deki gibi bulunur.

$v_{\mathrm{x}}=\frac{1}{\mathrm{EI}(\Delta \mathrm{t})}\left(\frac{\mathrm{Px}^{3}}{12}-\frac{\mathrm{PL}^{2} \mathrm{x}}{16}\right)$

Denklem (16)'da $\rho$ yerine $M_{1} / L$ ve $v_{x}$ yerine de denklem (17) konularak integral alındığında,

$\left(\mathrm{T}_{1}\right)_{\mathrm{e}}=\frac{1}{2} \mathrm{Mv}_{1}{ }^{2}+\mathrm{M}_{1}\left(\frac{1,0549 \mathrm{P}^{2} \mathrm{~L}^{6} 10^{(-4)}}{[\operatorname{EI}(\Delta \mathrm{t})]^{2}}\right)$

ifadesi elde edilir. Şekil 6'da $\mathrm{x}=\mathrm{L} / 2$ olduğunda $v_{x}=v_{1}$ 'dir. Denklem (17)'de $x$ yerine $L / 2, v_{x}$ yerine de $v_{1}$ konulduktan sonra eşitliğin her iki tarafının karesi alınıp uygun şekilde düzenlendiğinde, 
$\frac{v_{1}^{2}}{4,340}=\frac{\mathrm{P}^{2} \mathrm{~L}^{6} 10^{(-4)}}{[\mathrm{EI}(\Delta \mathrm{t})]^{2}}$

eşitliği elde edilir. Denklem (19)'da eşitliğin sol tarafı denklem (18)'de yerine yazılıp gerekli işlem yapıldıktan sonra

$\left(\mathrm{T}_{1}\right)_{\mathrm{e}}=\frac{1}{2} \mathrm{Mv}_{1}^{2}+0,2431 \mathrm{M}_{1} \mathrm{v}_{1}^{2}$

ifadesi bulunmuş olur. Denklem (15) ve denklem (20) ifadeleri de denklem (12)'de yerlerine konulup gerekli düzenleme yapıldıktan sonra denklem (21) elde edilir.

$\mathrm{K}_{\mathrm{e}}=\frac{\frac{1}{2} \mathrm{M}+0,2431 \mathrm{M}_{1}}{\frac{1}{2} \mathrm{M}}\left(\frac{\mathrm{v}_{1}}{\mathrm{v}_{0}}\right)^{2}$

Momentumun korunumu: Çarpışmada momentum korunmaktadır. $M_{1}$ kütlesindeki elastik kiriş ve $M$ kütlesindeki ağıllıktan oluşan sistemin çarpışmadan hemen önceki ve sonraki momentumlarına sırasıyla $\left(\mathrm{L}_{0}\right)_{\mathrm{e}}$ ve $\left(\mathrm{L}_{1}\right)_{\mathrm{e}}$ denilmiş̧ir. $\left(\mathrm{L}_{0}\right)_{\mathrm{e}}$, çarpışmadan hemen önce kiriş hareketsiz olduğu için sadece $M$ kütlesinden kaynaklanan momentuma eşittir (Denklem (22)).

$\left(\mathrm{L}_{0}\right)_{\mathrm{e}}=\mathrm{Mv}_{0}$

$\left(\mathrm{L}_{1}\right)_{\mathrm{e}}$, Şekil 6 dikkate alınarak denklem (23) ile ifade edilmiştir.

$\left(\mathrm{L}_{1}\right)_{\mathrm{e}}=\mathrm{Mv} v_{1}+2 \int_{0}^{\mathrm{L} / 2} \rho v_{\mathrm{x}} \mathrm{dx}$

Eşitlikteki ilk terim $\mathrm{M}$ kütlesinin momentumunu, ikinci terim ise elastik kirişin momentumunu göstermektedir. Denklem (23)'de $\rho$ yerine $\mathrm{M}_{1} / \mathrm{L}$ ve $v_{\mathrm{x}}$ yerine de denklem (17)'deki değeri konulup denklem içerisindeki integral işlemi yapıldığında,

$\left(\mathrm{L}_{1}\right)_{\mathrm{e}}=\mathrm{Mv}_{1}+\mathrm{M}_{1}\left(\frac{-10}{768}\right)\left(\frac{\mathrm{PL}^{3}}{\mathrm{EI}(\Delta \mathrm{t})}\right)$

ifadesi elde edilir. Denklem (17)'de x yerine $L / 2, v_{x}$ yerine de $v_{1}$ konulduktan sonra eşitliğin sağ tarafinda $\mathrm{PL}^{3} / \mathrm{EI}(\Delta \mathrm{t})$ ifadesi yalnız bırakıldığında,

$-48 v_{1}=\frac{\mathrm{PL}^{3}}{\mathrm{EI}(\Delta \mathrm{t})}$

eşitliği bulunur. Denklem (25)'de eşitliğin sol tarafındaki ifade denklem (24)'de eşitliğin sağ tarafındaki yerine konulup gerekli işlemler yapıldığında da denklem (26) elde edilir.

$\left(\mathrm{L}_{1}\right)_{\mathrm{e}}=\mathrm{Mv}_{1}+\mathrm{M}_{1}\left(0,625 v_{1}\right)$

Çarpışma öncesindeki ve sonrasındaki momentumlar eşit olduğu için denklem (22) ile denklem (26) birbirine eşitlenip $v_{1} / v_{0}$ ifadesi, eşitliğin sol tarafinda yalnız bırakıldığında,

$\frac{v_{1}}{v_{0}}=\frac{M}{M+0,625 M_{1}}$

denklemi elde edilir. Denklem (27), denklem (21)'de yerine konulduğunda denklem (11) elde edilmiş olur.

\section{3. $K_{p}$ ve $K_{e}$ 'nin Karşılaş̧tırılması (The Comparison of $K_{p}$ and $K_{e}$ )}

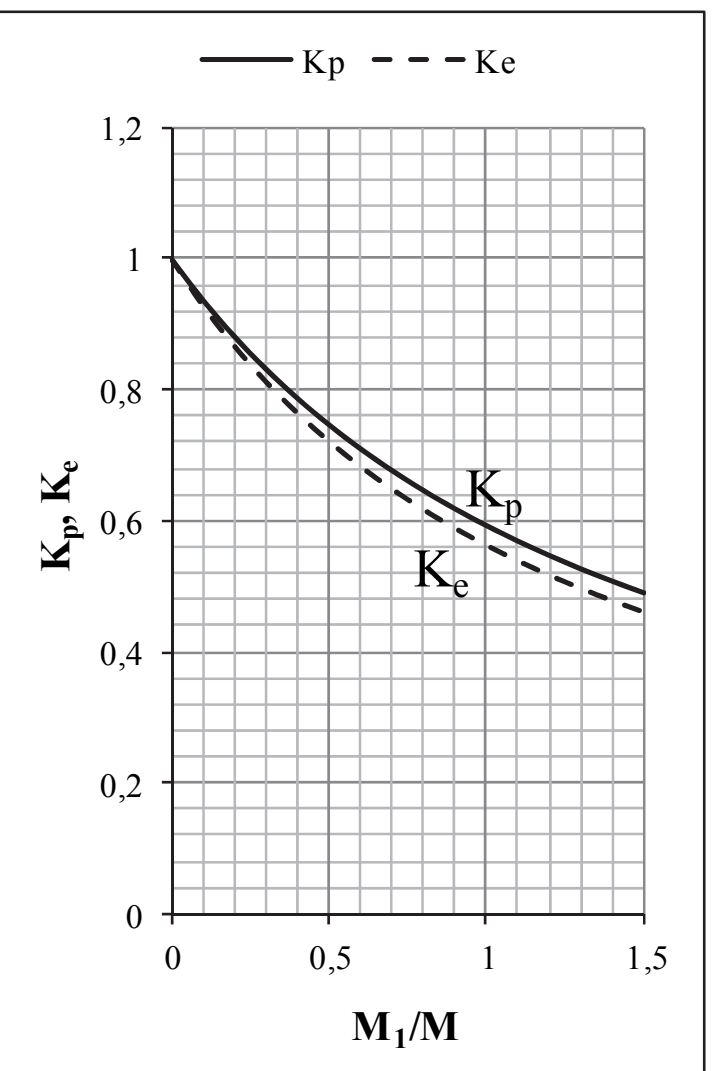

Şekil 7. $K_{p}$ ve $K_{e}$ 'nin $M_{1} / M$ 'e göre değişimi (Variation of $K_{p}$ and $K_{e}$ due to $M_{1} / M$ )

$K_{p}$ ve $K_{e}^{\prime}$ 'nin $M_{1} / M$ boyutsuz değiş̧enine göre değişimleri Şekil 7'deki grafikte gösterilmiştir. Grafiğe göre $\mathrm{M}_{1} / \mathrm{M}>0$ olduğunda $\mathrm{K}_{\mathrm{p}}, \mathrm{K}_{\mathrm{e}}$ 'den daha büyük değer almaktadır. $\mathrm{Bu}$ durum çarpma olayında basit mesnetli elastik kirişin basit mesnetli rijit plastik kirişe göre daha büyük oranda enerji sönümlediğini göstermektedir. İlk bakışta beklenmeyen bu durumun nedeni, elastik kirişin çarpışmada kiriş açıklığı boyunca deforme olmasıyla enerji sönümlenmesi; rijit plastik kirişte ise, sadece kiriş orta noktasında oluşan 
plastik mafsal ile sınırlı bir bölgede enerji sönümlenmesi olarak düşünülmüştür.

\subsection{Basit Mesnetli Rijit Plastik Kirişte Dönme} Açısı (The Rotation Angle in a Simply Supported Rigid Plastic Beam)

Basit mesnetli rijit plastik kirişin çarpışmadan kaynaklanan göçme şekli, Şekil 2 ile gösterilmişti. Şekil 2'de çarpışmadan hemen önce (kirişin açıklık ortası $\mathrm{y}=0$ seviyesindeyken) kiriş ve $\mathrm{M}$ kütlesinden oluşan sistemin $\mathrm{y}=\mathrm{y}_{\max }$ 'dan geçen yatay eksene göre potansiyel enerjisine $\left(\mathrm{P}_{1}\right)_{\mathrm{p}}$ denildiğinde,

$$
\left(\mathrm{P}_{1}\right)_{\mathrm{p}}=\mathrm{Mg}\left(\frac{\mathrm{L}}{2} \sin \theta\right)+\mathrm{M}_{1} \mathrm{~g}\left(\frac{\mathrm{L}}{4} \sin \theta\right)
$$

denklemi ile ifade edilir. Denklemde geçen ve birimi Radyan olan $\theta$ açısı çok küçük bir açı olduğu için $\sin \theta \approx \theta$ olmaktadır. Bu nedenle denklemde $\sin \theta$ yerine $\theta$ konulduğunda,

$$
\left(P_{1}\right)_{p}=\frac{L}{2} M g \theta+\frac{L}{4} M_{1} g \theta
$$

ifadesi elde edilir. Çarpışmadan hemen sonra sistemin toplam mekanik enerjisine $\left(E_{1}\right)_{p}$ denildiğinde $\left(E_{1}\right)_{p}$, denklem (30) ile ifade edilir.

$$
\left(\mathrm{E}_{1}\right)_{\mathrm{p}}=\left(\mathrm{T}_{1}\right)_{\mathrm{p}}+\left(\mathrm{P}_{1}\right)_{\mathrm{p}}
$$

Denklem (9)'da $v_{1}$, eşitliğin solunda yalnız bırakılıp, yeni eşitlik denklem (5)'de yerine konduğunda,

$\left(\mathrm{T}_{1}\right)_{\mathrm{p}}=\left(\frac{\mathrm{M}}{2}+\frac{\mathrm{M}_{1}}{6}\right)\left(\frac{1}{1+\frac{\mathrm{M}_{1}}{2 \mathrm{M}}}\right)^{2} \mathrm{v}_{0}{ }^{2}$

ifadesi bulunur. Denklem (29) ve denklem (31), denklem (30)' da yerlerine konulduğunda $\left(\mathrm{E}_{1}\right)_{\mathrm{p}}$,

$$
\begin{array}{r}
\left(E_{1}\right)_{p}=\left(\frac{M}{2}+\frac{M_{1}}{6}\right)\left(\frac{1}{1+\frac{M_{1}}{2 M}}\right)^{2} v_{0}^{2} \\
+\frac{L}{2} M g \theta+\frac{L}{4} M_{1} g \theta
\end{array}
$$

şeklinde bulunmuş olur. Rijit plastik kirişte çarpışma sonunda oluşan plastik mafsalın yapmış olduğu iş, $\mathrm{W}_{\mathrm{p}}$ ile gösterilsin. $\mathrm{W}_{\mathrm{p}}$, çarpışmadan hemen sonra kirişin sahip olduğu toplam mekanik enerji $\left(\mathrm{E}_{1}\right)_{\mathrm{p}}$ 'ye eşit olur [15], [16], [17]. Plastik mafsalın yapmış olduğu iş,

$\mathrm{W}_{\mathrm{p}}=\mathrm{M}_{\mathrm{p}}(2 \theta)$ denklemi ile bulunur. Yukarıdaki denklemde $M_{p}$ ifadesi, kiriş kesitinin plastik moment kapasitesini göstermektedir.

Denklem (32) ile denklem (33) birbirine eşitlenip $\theta$ açısı eşitliğin sol tarafında yalnız bırakıldığında denklem (34) elde edilmiş olur.

$$
\theta=\frac{\left(\frac{M}{2}+\frac{M_{1}}{6}\right)\left(\frac{1}{1+\frac{M_{1}}{2 M}}\right)^{2} v_{0}^{2}}{2 M_{p}-\frac{L}{2}\left(M+\frac{M_{1}}{2}\right) g}
$$

\subsection{Ankastre Mesnetli Rijit Plastik Kirişte Dönme} Açısı (The Rotation Angle in a Fixed End Supported Rigid Plastic Beam)

İki ucu ankastre mesnetli rijit plastik kirişin çarpışmadaki plastik göçme mekanizması Şekil 8'de gösterilmiştir.

Çarpışma ile birlikte kiriş orta noktasında ve mesnetlerde birer tane olmak üzere kiriş üzerinde toplam üç adet plastik mafsal oluşmaktadır. Çarpışma ile mesnetlerde ve kiriş orta noktasında oluşan plastik mafsallar arasında kalan iki adet L/2 uzunluğundaki kiriş parçası (eksenleri boyunca doğrusal kalarak) plastik mafsallar etrafinda dönmektedirler. Ankastre mesnetli kirişteki dönme açısı $\theta^{\prime}$ ile gösterilmiştir.

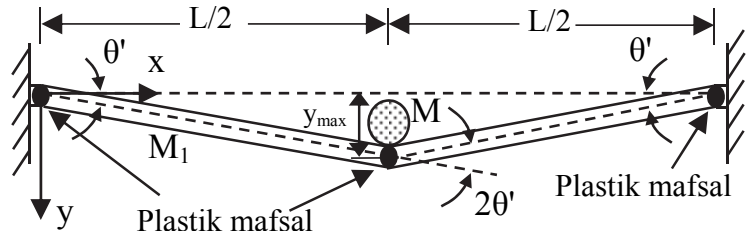

Şekil 8. İki ucu ankastre mesnetli rijit plastik kirişin kırılma mekanizması (The failure mode of a fixed end supported rigid plastic beam)

Çarpışma sonrasında kirişin sahip olduğu toplam mekanik enerji ile üç adet plastik mafsalın yaptığı işlerin toplamı birbirine eşittir. Plastik mafsalların yaptığı toplam iş,

$$
\begin{aligned}
& \mathrm{W}_{\mathrm{p}}{ }^{\prime}=\mathrm{M}_{\mathrm{p}}\left(2 \theta^{\prime}\right)+\mathrm{M}_{\mathrm{p}}\left(\theta^{\prime}\right)+\mathrm{M}_{\mathrm{p}}\left(\theta^{\prime}\right) \\
& \mathrm{W}_{\mathrm{p}}{ }^{\prime}=\mathrm{M}_{\mathrm{p}}\left(4 \theta^{\prime}\right)
\end{aligned}
$$

eşitlikleri ile gösterilmiştir. Basit mesnetli rijit plastik kiriş için elde edilmiş olan denklem (32) burada da geçerlidir. Ankastre mesnetli rijit plastik kirişin çarpışma sonrasındaki toplam mekanik enerjisine $\left(\mathrm{E}_{1}\right)_{\mathrm{p}}{ }^{\prime}$ denildiğinde ve denklem (32)'de $\theta$ açısı yerine $\theta^{\prime},\left(\mathrm{E}_{1}\right)_{\mathrm{p}}$ yerine de $\left(\mathrm{E}_{1}\right)_{\mathrm{p}}{ }^{\prime}$ konulduğunda, 


$$
\begin{aligned}
\left(E_{1}\right)_{\mathrm{p}}{ }^{\prime}=\left(\frac{\mathrm{M}}{2}+\right. & \left.\frac{\mathrm{M}_{1}}{6}\right)\left(\frac{1}{1+\frac{\mathrm{M}_{1}}{2 \mathrm{M}}}\right)^{2} v_{0}{ }^{2} \\
& +\frac{\mathrm{L}}{2} \mathrm{Mg} \theta^{\prime}+\frac{\mathrm{L}}{4} \mathrm{M}_{1} \mathrm{~g} \theta^{\prime}
\end{aligned}
$$

eşitliği elde edilir. Denklem (36) ve denklem (37) birbirine eşitlendiğinde $\theta^{\prime}$ açısı, denklem (38)'deki gibi bulunmuş olur. Denklem (34) ve denklem (38) karşılaştırıldığında ankastre mesnetli rijit plastik kiriş için elde edilen $\theta^{\prime}$ açısının basit mesnetli rijit plastik kiriş için elde edilen $\theta$ açısından daha küçük olduğu görülmüştür (Denklem (39)).

$$
\theta^{\prime}=\frac{\left(\frac{M}{2}+\frac{M_{1}}{6}\right)\left(\frac{1}{1+\frac{M_{1}}{2 M}}\right)^{2} v_{0}^{2}}{4 M_{p}-\frac{L}{2}\left(M+\frac{M_{1}}{2}\right) g}
$$

$\Rightarrow \theta^{\prime}<\theta$

\section{SONUÇLAR (CONCLUSIONS)}

Rijit plastik cisimlerin düşük hızlı çarpma yükleri altındaki davranışını incelemek amacıyla, birinci aşamada rijit cisimler dinamiğinin temel ilkelerinden enerjinin ve momentumun korunumu kullanılmıştır. Çalışma kapsamında dikkate alınan çarpma, plastik bir çarpma olduğundan toplam mekanik enerji kayba uğramıştır. Momentumun korunumu ilkesinden yararlanılarak çarpan cismin ve kiriş parçalarının çarpma sonrasındaki ortak ilk hızı hesaplanmıştır. Araştırmanın ikinci aşamasında kirişlerin plastik analizi, veya limit analizi yapılarak, plastik dönme açı1s1 formülü, plastik moment kapasitesine bağlı olarak türetilmiştir.

Bütünüyle elastik ve rijit plastik kirişlerin davranışlarının karşılaştırılması amacıyla, çarpan kütlenin kiriş kütlesine oranına bağlı olarak, enerji kayıp oranlarının bir karşılaştırılması yapılmıştır. Bunun sonucunda bütünüyle elastik bir kirişin çarpma yükü altındaki enerji kaybı, rijit plastik kiriştekine göre daha fazla çımıştır. Bunun nedeni, rijit plastik kirişte deformasyonun plastik mafsal üzerinde sınırlı olması; elastik kirişte ise deformasyonun kiriş açıklığı boyunca yayılmasıdır.

Ankastre mesnetli rijit plastik kirișteki plastik dönme açısı ile basit mesnetli rijit plastik kirişteki plastik dönme açısı karşılaştırılmıştır. Formülasyon sonucunda basit mesnetli kirişteki plastik dönme açısının ankastre mesnetli kirişteki dönme açısından daha büyük olduğu sonucuna varılmıştır. Böylece, analitik formülasyon tamamlanmış, bu konuda deneysel ve nümerik araştırmalara devam edilebilmesi için teorik bir temel oluşturulmuştur.

\section{SEMBOLLER (SYMBOLS)}

$\Delta$ t Bir cismin y mesafesi kadar yol alırken geçen süre

E Kirişin elastisite modulü

$\left(\mathbf{E}_{1}\right)_{\mathbf{p}}$ Basit mesnetli rijit plastik kiriş ve M kütlesinin çarpışmadan hemen sonraki toplam mekanik enerjisi

$\left(\mathbf{E}_{1}\right)_{\mathrm{p}}{ }^{\prime}$ Ankastre mesnetli rijit plastik kiriş ve $\mathrm{M}$ kütlesinin çarpışmadan hemen sonraki toplam mekanik enerjisi

g Yerçekimi ivmesi

h $\quad M$ kütlesinin kiriş üzerine düşürülme yüksekliği

I Kiriş kesitinin ağırlık merkezinden geçen eksene göre atalet momenti

$\mathbf{K}_{\mathbf{e}} \quad$ Basit mesnetli elastik kirişte enerji sönümleme oranı

$\mathbf{K}_{\mathbf{p}} \quad$ Basit mesnetli rijit plastik kirişte enerji sönümleme oranı

L Kiriş uzunluğu

$\left(\mathbf{L}_{0}\right)_{\mathbf{e}} \quad$ Elastik kiriş ve $\mathrm{M}$ kütlesinin çarpışmanın hemen öncesindeki momentumu

$\left(\mathbf{L}_{1}\right)_{\mathbf{e}}$ Elastik kirişi ve $\mathrm{M}$ kütlesinin çarpışma sonrası momentumu

$\left(\mathbf{L}_{0}\right)_{\mathbf{p}} \quad$ Rijit plastik kiriş ve $\mathrm{M}$ kütlesinin çarpışmanın hemen öncesindeki momentumu

$\left(\mathbf{L}_{1}\right)_{\mathbf{p}} \quad$ Rijit plastik kiriş ve $\mathrm{M}$ kütlesinin çarpışma sonrası momentumu

M Kiriş üzerine düşürülen ağırlığın kütlesi

$\mathbf{M}_{\mathbf{1}} \quad$ Kirişin kütlesi

$\mathbf{M}_{\mathbf{p}} \quad$ Kiriş kesitinin plastik moment kapasitesi

p Kirişin birim boyunun ağırlığ $1\left(\mathrm{M}_{1} / \mathrm{L}\right)$

P Noktasal statik yük

$\left(\mathbf{P}_{1}\right)_{\mathbf{p}} \quad$ Rijit plastik kirişin ve $\mathrm{M}$ kütlesinin çarpışmanın ilk anında $\mathrm{y}_{\max }$ seviyesinden geçen yatay eksene göre toplam potansiyel enerjisi

$\left(\mathbf{T}_{\mathbf{0}}\right)_{\mathrm{e}} \quad$ Elastik kiriş ve $\mathrm{M}$ kütlesinin çarpışmanın hemen öncesinde toplam kinetik enerjisi

$\left(\mathbf{T}_{1}\right)_{\mathbf{e}}$ Elastik kiriş ve $\mathrm{M}$ kütlesinin çarpışma sonrasında toplam kinetik enerjisi

$\left(\mathbf{T}_{\mathbf{0}}\right)_{\mathbf{p}}$ Rijit plastik kiriş ve $\mathrm{M}$ kütlesinin çarpışmanın hemen öncesinde toplam kinetik enerjisi

$\left(\mathbf{T}_{1}\right)_{\mathrm{p}} \quad$ Rijit plastik kiriş ve $\mathrm{M}$ kütlesinin çarpışma sonrasında toplam kinetik enerjisi

$\boldsymbol{\theta}$ Basit mesnetli rijit plastik kirişte dönme açısı

$\boldsymbol{\theta}^{\prime} \quad$ Ankastre mesnetli rijit plastik kirişte dönme açıs1

vort Ortalama hiz

$\boldsymbol{v}_{\mathbf{0}} \quad$ M kütlesinin çarpışmadan hemen önceki hızı

$\boldsymbol{v}_{\mathbf{1}} \quad$ M kütlesinin ve kiriş açıklık orta noktasının çarpışma sonrasındaki ortak hızı 
$\mathbf{v}_{\mathbf{x}} \quad$ Kiriş üzerinde mesnetten $\mathbf{x}$ kadar uzaklıktaki bir noktanın çarpışma sonrası hızı

$\mathbf{W}_{\mathbf{p}} \quad$ Basit mesnetli rijit plastik kirişte plastik mafsalın yaptığ 1 iş

$\mathbf{W}_{\mathbf{p}}{ }^{\prime} \quad$ Ankastre mesnetli rijit plastik kirişte plastik mafsalın yaptığ 1 iş

$\mathbf{x} \quad$ Kiriş üzerindeki bir noktanın mesnete olan uzaklığ 1

$\mathbf{y} \quad$ Kiriş üzerinde mesnetten $\mathrm{x}$ uzaklıktaki bir noktanın yaptığı düşey deplasman

$\mathbf{y}_{\max } \quad$ Rijit plastik kirişin açıklık orta noktasının yaptığı maksimum deplasman

\section{KAYNAKLAR (REFERENCES)}

1. Yu, T.X., Yang, J.L. ve Reid, S.R., "Dynamic behavior of double cantilever beams subjected to impact", International Journal of Pressure Vessels and Piping, Cilt 78, No 1, 49-57, 2001.

2. Yu, T.X., Yang, J.L. ve Reid, S.R., "Deformable body impact: dynamic plastic behaviour of a moving free-free beam striking the tip of a cantilever beam ", International Journal of Solids and Structures, Cilt 38, No 2, 261-287, 2001.

3. Yang, J.L., Liu, X.H. ve Reid, S.R., "Dynamic plastic behavior of a free-free beam striking the mid-span of a clamped beam with shear and membrane effects considered", International Journal of Mechanical Sciences, Cilt 45, No 5, 915-940, 2003.

4. Yang, J.L., Yu, T.X. ve Reid, S.R., "Dynamic behaviour of a rigid, perfectly plastic free-free beam subjected to step-loading at any crosssection along its span", International Journal of Impact Engineering, Cilt 21, No 3, 165-175 1998.

5. Wen, H.M., Reddy, T. Y. ve Reid, S.R., "Deformation and failure of clamped beams under low speed impact loading", International Journal of Impact Engineering, Cilt 16, No 3, 435-454, 1995.

6. Liu, J.H. ve Jones, N., "Dynamic response of a rigid plastic clamped beam struck by a mass at any point on the span", International Journal of Solids and Structures, Cilt 24, No 3, 251-270, 1988.

7. Kantar, E., Arslan. A. ve Anıl, Ö., "Beton dayanımındaki değişimin çarpma davranışına etkisi", Journal of The Faculty of Engineering and Architecture of Gazi University, Cilt 26, No 1, 115-123, 2011.

8. Kishi, N. ve Bhatti, A.Q., "An equivalent fracture energy concept for nonlinear dynamic response analysis of prototype RC girders subjected to falling-weight impact loading", International Journal of Impact Engineering, Cilt 37, No 1, 103-113, 2010.

9. Saatci, S. ve Vecchio, F.J., "Effects of shear mechanisms on impact behavior of reinforced concrete beams", ACI Structural Journal, Cilt 106, No 1, 78-86, 2009.

10. Saatci, S. ve Vecchio, F.J., "Nonlinear finite element modeling of reinforced concrete structures under impact loads", ACI Structural Journal, Cilt 106, No 5, 717-725, 2009.

11. Harsoor, R. ve Ramachandra, L.S., "Influence of notch on the elastic-plastic response of clamped beams subjected to low velocity impact", International Journal of Impact Engineering, Cilt 36, No 8, 1058-1069, 2009.

12. Bambacha, M.R., Jamaa, H., Zhaoa, X.L. ve Grzebieta, R.H., "Hollow and concrete filled steel hollow sections under transverse impact loads", Engineering Structures Cilt 30, No 10, 28592870, 2008

13. Gültop, T., Alyavuz, B. ve Yılmaz, M.C., "Plastic Collapse of Beams under Impact Loading", 6. Mühendislik ve Teknoloji Sempozyumu, Çankaya Üniversitesi, Ankara, 63-66, 25-26 Nisan 2013.

14. Young, W.C., "Dynamic and Temperature Stresses", Roark's Formulas for Stress and Strain, Mc Graw Hill, Sixth Edition, New York, A.B.D., 710-720, 1989.

15. Wasti, S.T., "Yıkıllı̧ıı Bazı Misalleri”, Limit Analizi, Orta Doğu Teknik Üniversitesi Mühendislik Fakültesi Yayınları, Ankara, Türkiye, 13-24, 1968.

16. Neal, B.G., "Basic Theorems and Simple Examples", The Plastic Methods of Structural Analysis, Chapman and Hall, Londra, İngiltere, 18-46, 1981.

17. Martin, J.B., "Limit Analysis of Beams and Frames", Plasticity: Fundamentals and General Results, MIT Press, Londra, İngiltere, 408-420, 1975. 